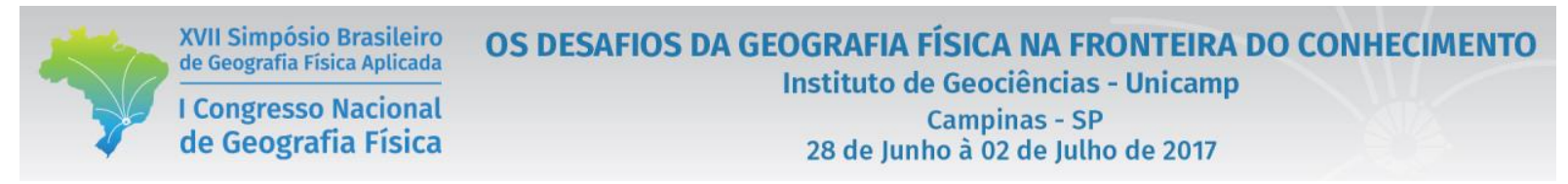

\title{
MAPEAMENTO GEOMORFÓGICO DO BAIXO CURSO DA BACIA HIDROGRÁFICA DO RIO ANIL, ILHA DO MARANHÃO
}

Anny Karolyny Oliveira Portela ${ }^{(a)}$; Leandro Coelho Souza ${ }^{(b)}$; Gilberlene Serra Lisboa ${ }^{(c)}$ José Fernando Rodrigues Bezerra ${ }^{(\mathrm{d})}$

(a)(GEOMAP, GEOGRAFIA/UEMA), akoliveiraportela@ gmail.com

(b)(GEOMAP, GEOGRAFIA/UEMA), leandro_coelho02@ hotmail.com

(c)(GEOMAP, GEOGRAFIA/UEMA), gilberlene_ok@hotmail.com

(d)(GEOMAP, DHG/UEMA), fernangeo@yahoo.com.br

Eixo: SISTEMA GEOMORFOLÓGICOS: ESTRUTURAS, DINÂMICAS E PROCESSOS.

\begin{abstract}
Resumo
Os estudos geomorfológicos têm como base o planejamento urbano e ambiental, que auxiliam na tomada de decisão por gestores. Desta forma, o objetivo desta pesquisa é mapear a organização do relevo e representar cartograficamente o baixo curso da bacia hidrográfica do rio Anil, com base na classificação taxonômica proposta por Ross, tendo como destaque o quinto e sexto táxon, pois enquadram-se neste estudo. Dentro dos procedimentos metodológicos encontram-se levantamento bibliográfico e cartográfico, atividade de campo e mapeamento. Nesta última etapa o uso de shapes e curvas de nível de cartas topográficas DSG/ME - MINTER, correspondente as cartas 13, 14, 22 e 23, com escala de 1:10.000 essencial para o mapeamento com o auxílio do software ArcGIS. Com o Objetivo de auxiliar nas interpretações e analises da evolução do relevo.
\end{abstract}

Palavras chave: mapeamento, geomorfoloia e processos erosivos.

\section{Introdução}

O conhecimento geomorfologico revela à importância de estudar o relevo, visto que se dissemina por várias áreas do saber, estendendo-se desde de o planejamento urbano ao ambiental. O objetivo da geomorfologia é estudar as formas de relevo, analisando e compreendendo as formas antigas e atuais, observando a dinâmica da paisagem, derivado de diversos processos (CASSETI, 2005).

Para Florenzano (2008), a geomorfologia possui quatro variáveis: morfologia, morfogênese, a morfodinâmica e a morfocronologia, elementos relevantes para o equilíbrio do geossistema. Uma vez que possui uma ferramenta eficaz para representar graficamente e espacialmente, os objetos e fenômenos estudados, a cartografia geomorfológica, fundamental para à produção de mapas geomorfológicos. Vale lembrar que no Brasil, a cartografia geomorfológica já existia, mas de forma tímida, e somente em alguns estados, como por exemplo, São Paulo. Desta forma, estes produtos só tiveram seu estopim a partir de 1970, com o Projeto RAMBRASIL, por apresentar maior detalhamento e tornando-os mais específicos, reduzidos em extensão espacial e não sistematizados. 
Ross (2007), afim de mapear as formas de relevo apresenta uma classificação taxonômica divididas em seis unidades abrangendo diversas formas de modelados. Silva (2012), define o mapa geomorfológico como importante instrumeto na pesquisa da paisagem. Pois é a base da pesquisa, e não apenas a sua concretização gráfica, ou seja, é simultaneamente o instrumento que direciona a pesquisa e a sua síntese. (TRICART, 1965), A elaboração de um mapa geomorfológico, requer uma análise conceitual de morfodinâmica, partir de um contexto regional, por ser facilmente aplicado em ambientes urbanos.

Partindo do principio que os sistemas naturais são constantimentes transformados, tanto pela ação humana, como pelo ciclo natural. Sendo o homem o principal agente modificador da paisagem. Guerra (2001), afirma que os estudos geomorfológicos atuais, estão relacionados aos processos erosivos que passam por fases, inciniando com a ação do efeito splash, encrotamentos e a formação de processos erosivos lineares, evoluindo para uma ravina e chegando ao maior estágio de evolução, uma voçoroca. Com isso vale ressaltar que os processos erosivos da área de estudo estão relacionandos a geomorfologia costeira. Nesse contexto, a pesquisa está relacionada aos estudos relacionados ao mapeamento geomorfológico do baixo curso da bacia do rio Anil, sendo um dos principais rios da Ilha do Maranhão.

\section{Procedimentos técnico-operacionais}

Para a execução deste trabalho de pesquisa, foram realizados trabalhos de gabinete e campo, com o objetivo de coletar, organizar e analizar os dados obtidos gerando um banco de dados, para a elaboração de produtos tematicos com a utilização do software ArcGis 10.2 (lincença EFL (999703439). Nas atividades empiricas realizada no Bairro Bequimão, na voçoroca Santa Eulália, na cidade de São Luis - MA, foram coletados coordenadas geográficas, com o uso de GPS (Sistema de Posicionamento Global), fundamental para o mapeamento, processamento e espacialização dos dados relacionados as caracteristicas geoambientais do baixo curso da bacia hidrográfica do rio Anil. Assim, a utilização de cartas DSG/ME - MINTER (Diretoria do Serviço Geográfico do Ministério do Exército), de 1980, o baixo curso da bacia do rio Anil, corresponde as Cartas 13,14, 22 e 23, em escala de 1:10.000, que foram georreferenciadas com o auxílio da ferramenta do softwere ArcGis 10.2. Posteriomente, a delimitação do baixo curso da bacia hidrográfica do rio Anil, definido a partir das cartas DSG/ME - MINTER, levando em consideração as curvas de nível com intervalos de $5 \mathrm{~m}$ (metros) e as drenagens, fundamental para a confecção do mapa geomorfologia.

Quanto a produção do mapa geomorfológico, foram usados os shapes em escala 1:60.000, a partir da edição começou a ganhar formas. O mapa apresentado neste estudo, representam o baixo curso da hidrográfica do rio Anil e a localização da Voçoroca Santa Eulália. 


\section{Resultados e discussão}

A área de estudo apresenta aspectos geoambientais marcantes, pois o rio Anil está situado na porção Noroeste da Ilha do Maranhão, fazendo parte do complexo sistema estuarino Golfão Maranhense. Na referida Ilha, existem vários sistemas de drenagem, um deles o rio Anil, sendo o segundo maior rio em extensão, com desembocadura à Noroeste da Ilha do Maranhão, na Baia de São Marcos.

A geologia da bacia do rio Anil, apresenta formações litoestratigráficas do grupo Barreiras e as formações de depósitos aluvionares e coluvionares, bem como também depósitos de mangues. Quanto a estrutura geomorfológica da Ilha do Maranhão, de acordo com o Dantas (2013), o relevo do litoral maranhense, apresenta três padrões morfológicos, ao Noroeste, têm como características as "Reentrâncias maranhenses", com a planície costeira povoada por florestas de manguezais. Onde está localizado o baixo curso da bacia do rio Anil, desse modo, a morfologia da área de estudo apresenta as características dessa planície costeira. Inseridos dentro dos padrões geomorfológicos da Ilha do Maranhão, as colinas esparsas, planície fluvial, planície de maré, tabuleiros com topos planos e vertentes fazem parte do conjunto geomorfológico do baixo curso da bacia hidrográfica do rio Anil. Silva (2012), afirma que as colinas esparsas são encontradas comumente nas porções centro-sudeste, sul e noroeste da Ilha do Maranhão, dessa forma a área de estudo é contemplada por esta por esta forma de relevo, na qual a maior parte do baixo curso da bacia hidrográfica do rio Anil é representada, isso comparada com as demais formas, onde é possível ser observado na figura 01.

Ainda de acordo com Silva (2012), as colinas esparsas recobrem quase toda a Ilha do Maranhão, desse modo o baixo curso da bacia do rio Anil, também é contemplado por esta forma de relevo em sua grande parte. $\mathrm{Na}$ área de estudo a planície de maré facilmente observada, pois se interiorizam na Ilha por meio de canais de drenagens, em decorrência da grande amplitude de maré. É possível verificar a ocorrência de topos tabulares, localizados na porção central da Ilha e estendendo-se até meados do baixo curso da bacia do rio anil. Com relação aos tabuleiros de topos planos, é compreendido em geral por entre as rupturas do relevo da área de estudo, onde são representados também nas cartas topográficas, outra característica importante é a utilização destas cartas para delimitar o baixo curso da bacia hidrográfica do rio Anil. 
Figura 01: Mapa geomorfológico do baixo curso da Bacia do rio Anil

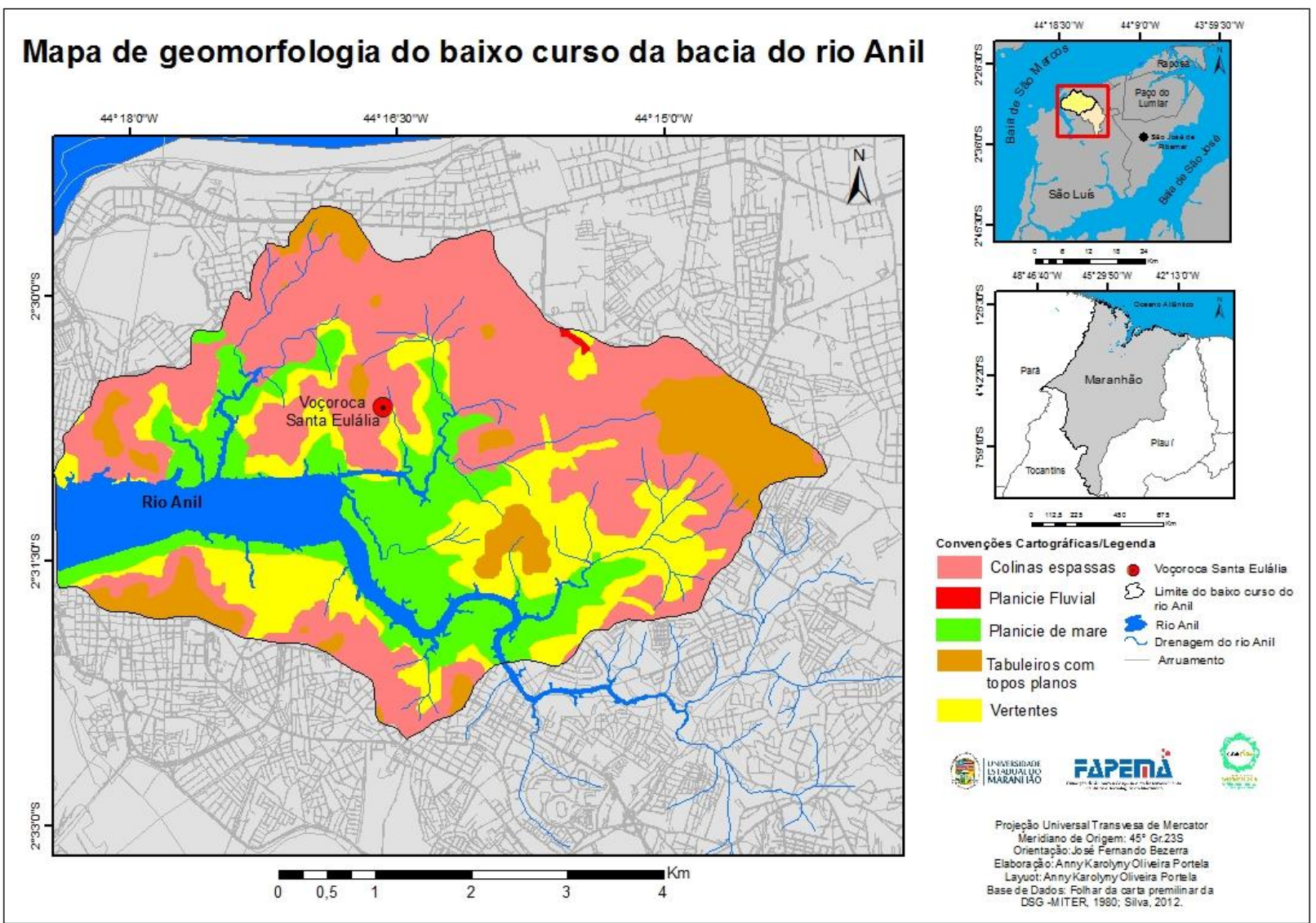

Fonte: Portela, 2017.

\section{Considerações finais}

No baixo curso da bacia hidrográfica do rio Anil, com o auxílio da classificação taxonômica adotada, proposta por Ross (1992), e com base no material bibliográfico levantado, o terceiro e o quarto táxon onde as formas de são divididas em três partes; formas estruturais, erosivas e de acumulação enquadraram-se no perfil desta pesquisa, pois há ocorrência de processos erosivos acelerados, como por exemplo, a Voçoroca Santa Eulália.

As informações oferecidas através no Mapeamento Geomorfológico, tem como finalidade auxiliar seja nas interpretações, ou análises da evolução do relevo. O que tornou possível através da utilização de técnicas de geoprocessamento.

\section{Agradecimentos}


A Deus pelo dom da vida.

Ao Programa Institucional de Bolsas de Iniciação Científica (PIBIC) e a Fundação de Amparo à Pesquisa e Desenvolvimento Científico do Maranhão (FAPEMA), pelo financiamento do projeto de pesquisa.

Ao Grupo de pesquisa Geomorfologia e Mapeamento (GEOMAP) pelo incentivo ao desenvolvimento deste trabalho, em especial o Professor Dr. Fernando Bezerra, que foi fundamental no desenvolvimento da pesquisa.

\section{Referencias}

CASSETI, Valter. GEOMORFOLOGIA. [S.1.]: [2005] Disponível em: < http://www.funape.org.br/geomorfologia/ >. Acesso em: 24 de novembro de 2016.

DANTAS, Marcelo Eduardo; SHINZATO, Edgar; BANDEIRA, Iris Celeste; SOUZA, Lívia Vargas de; RENK, Jennifer Fortes Cavalcante. COMPARTIMENTAÇÃo GEOMORFOLÓGICA. In BANDEIRA, Iris Celeste Nascimento (organizadora). Geodiversidade do estado do Maranhão. Teresina, 2013.

FLORENZANO, T. G. GEOMORFOLOGIA: CONCEITO E TECNOLOGIAS ATUAIS. São Paulo: Oficina de textos. 2008.

GUERRA, A. J. T. PROCESSOS EROSIVOS NAS ENCOSTAS. In: GUERRA, A. J. T. e CUNHA, S. B. (organizadores). GEOMORFOLOGIA: UMA ATUALIZAÇÃO DE BASES E CONCEITOS. $4^{\mathrm{a}}$ ed. Rio de Janeiro: Bertrand Brasil. 2001.

ROSS, Jurandy Luciano Sanches. O REGISTRO CARTOGRÁFICO DOS FOTOS GEOMORFOLÓGICOS E A QUESTÃO DA TAXONOMIA DO RELEVO. Revista do Departamento de Geografia, n. 6. FFLCH-USP, 1992.

ROSS, Jurandy Luciano Sanches. GEOMORFOLOGIA: AMBIENTE E PLANEJAMENTO. 8. Ed., $1^{\circ}$ reimpressão, Contexto. São Paulo, 2007.

SILVA, Quésia Duarte da. MAPEAMENTO GEOMORFOLÓGICO DA ILHA DO MARANHÃo. Presidente Prudente, 2012.

TRICART, Jean. ECODINÂMICA. Fundação do Instituto Brasileiro de Geografia e Estatística. Rio de Janeiro - RJ, 1965. 